\title{
Setting of noninvasive pressure support in young patients with cystic fibrosis
}

\author{
B. Fauroux*, F. Nicot*, S. Essouri*, N. Hart", A. Clément", M.I. Polkey ${ }^{\Uparrow}$, F. Lofaso ${ }^{+}$
}

Setting of noninvasive pressure support in young patients with cystic fibrosis. B. Fauroux, F. Nicot, S. Essouri, N. Hart, A. Clément, M.I. Polkey, F. Lofaso. (C) ERS Journals Ltd 2004.

ABSTRACT: The aim of the current study was to compare a clinical noninvasive method of setting up noninvasive pressure support ventilation (PS-NI) in young patients with cystic fibrosis (CF), based on parameters such as breathing frequency, arterial oxygen saturation and comfort rating, with a more invasive method (PS-I) targeted at optimising unloading of the inspiratory muscles and enhancing patient-ventilator synchronisation.

PS-NI and PS-I were compared in random order in 10 children with CF.

PS-NI differed from PS-I with regard to the level of inspiratory pressure $(n=5)$, rate of inspiratory pressurisation $(n=1)$, inspiratory trigger sensitivity $(n=2)$ and expiratory trigger sensitivity $(n=5)$. Although both methods modified breathing pattern, improved oxygen saturation and reduced diaphragmatic pressure time product $\left(450 \pm 91 \mathrm{cmH}_{2} \mathrm{O} \cdot \mathrm{s}^{-1} \cdot \mathrm{min}^{-1}\right.$ during spontaneous breathing, and $129 \pm 125$ and $104 \pm 75 \mathrm{cmH} \mathrm{H}_{2} \mathrm{O} \cdot \mathrm{s}^{-1} \cdot \mathrm{min}^{-1}$ during PS-NI and PS-I, respectively), patient-ventilator synchrony and patient comfort were enhanced more during PS-I.

In young patients with cystic fibrosis, setting up pressure support using a clinical noninvasive approach based on easily measurable parameters, such as respiratory rate and comfort rating, is as effective as a more invasive technique based on unloading of the inspiratory muscles and optimising patient-ventilator synchronisation. However, whilst the standard clinical method is satisfactory in the majority of patients, more invasive measurements should be considered in patients who have difficulty synchronising with the ventilator to enhance patient tolerance and compliance.

Eur Respir J 2004; 24: 624-630.
*Paediatric Pulmonary Dept and Research Unit INSERM E 213, Armand Trousseau Hospital, Assistance Publique - Hôpitaux de Paris, Paris, "Paediatric Intensive Care Unit, Bicêtre Hospital, Assistance Publique Hôpitaux de Paris, Le Kremlin Bicêtre, and ${ }^{+}$Physiology Dept, Raymond Poincaré Hospital, Assistance Publique - Hôpitaux de Paris, Garches, France. Respiratory Muscle Laboratory, Royal Brompton Hospital, London, UK.

Correspondence: B. Fauroux, Service de Pneumologie Pédiatrique and Research unit INSERM E 213, Hôpital d'Enfants Armand Trousseau, AP-HP 28, avenue du Docteur Arnold Netter, 75012 Paris, France.

Fax: 33144736718

E-mail: brigitte.fauroux@trs.ap-hop-paris.fr

Keywords: Cystic fibrosis, noninvasive mechanical ventilation, patient-ventilator synchronisation, pressure support ventilation, work of breathing

Received: December 122003

Accepted after revision: May 202004

This study was supported by Vaincre la Mucoviscidose (VLM), Assistance Publique Hôpitaux de Paris, University Pierre et Marie Curie (Paris IV), INSERM, and Saime, Savigny le Temple, France.
Although noninvasive positive pressure ventilation (NPPV) is less commonly used in patients with cystic fibrosis (CF) compared to other chronic lung diseases, a definite physiological rationale has been demonstrated for its use in young $\mathrm{CF}$ patients with advanced lung disease [1]. Recently, it has been shown that, as the lung disease progresses in these young patients with $\mathrm{CF}$, there is a fall in the forced expiratory volume in one second (FEV1), and the patients develop a compensatory mechanism of rapid shallow breathing pattern in an attempt to reduce the inspiratory muscle load [1]. Although this breathing strategy maintains an adequate level of ventilation, the partial arterial carbon dioxide pressure $\left(\mathrm{Pa}, \mathrm{CO}_{2}\right)$ rises, reflecting a fall in the efficiency of the respiratory muscle pump to clear $\mathrm{CO}_{2}$ [1]. Furthermore, severe ventilation-perfusion mismatching contributes to the impairment of gas exchange and, in particular, hypercapnia [2]. Short-term physiological studies, during wakefulness and sleep, have demonstrated that NPPV increases minute ventilation $\left(V^{\prime} \mathrm{E}\right)$, reduces respiratory muscle load and work of breathing, and thus improves alveolar ventilation in patients with $\mathrm{CF}$ [3-5]. Despite these encouraging results, NPPV is not part of the routine management of severe lung disease in CF. A possible explanation for this scepticism could be the less than optimal use of NPPV with regard to the appropriate ventilator settings in these patients.

NPPV can be set in one of two ways. A clinically driven technique may be used, during which the different ventilator variables are adjusted according to noninvasive parameters, such as pulse oximetry $\left(\mathrm{Sa}, \mathrm{O}_{2}\right)$, respiratory rate, $V^{\prime} \mathrm{E}$ and comfort of the patient $[3,6]$. These parameters are indirect markers that indicate an increase in alveolar ventilation, but they provide no data on the unloading of the respiratory muscles, which can only be assessed by acquiring electromyographic (EMG) measurements or quantifying the pressures generated by the respiratory muscles. Although the disadvantage of the EMG or pressure technique is that it is relatively invasive, major advantages include the ability to quantify respiratory muscle unloading [7] and evaluate patient-ventilator synchronisation [8, 9]. Furthermore, as physical examination and noninvasive monitoring are unreliable indicators for assessing the level of respiratory work with inappropriate ventilator settings increasing respiratory work [10], a more thorough invasive assessment may be necessary to ensure the optimal ventilator settings and patient compliance. 
The aim of the current study was to compare, in young patients with $\mathrm{CF}$, a clinical noninvasive method of setting up noninvasive pressure support ventilation (PS-NI), based on parameters such as breathing frequency, arterial oxygen saturation and comfort rating, with a more invasive method (PS-I), targeted at optimising the unloading of the inspiratory muscles and patient-ventilator synchronisation.

\section{Material and methods}

\section{Patients and experimental apparatus}

Informed consent was obtained from each patient and their parents. The protocol was part of the routine evaluation, with five patients being naive to NPPV (patients 4, 5, 8, 9 and 10).

Only patients in a stable state who fulfilled the defined criteria were enrolled into the study. These included: daytime hypercapnia $\left(\mathrm{Pa}_{\mathrm{a}} \mathrm{CO}_{2}>6 \mathrm{kPa}(45 \mathrm{mmHg})\right)$ and/or symptoms of nocturnal hypoventilation characterised by sleep disturbance; morning headaches and/or daytime sleepiness and fatigue; and nocturnal hypoxaemia with $>20 \%$ of sleep time spent with a $\mathrm{Sa}, \mathrm{O}_{2}<90 \%$ and a increase of mean transcutaneous carbon dioxide tension $P_{C_{2}}>1.3 \mathrm{kPa}(10 \mathrm{mmHg})$ between wakefulness and sleep [11, 12]. Arterialised earlobe capillary blood gases and forced expiratory flows were obtained during the 24-h period preceding the study session as part of the routine assessment [13, 14]. The criteria for exclusion were any one of the following: a history of pneumothorax in the 2 previous yrs; severe nasal obstruction due to nasal polyps; allergy to lidocaine; fever $>38^{\circ} \mathrm{C}$; hypercapnic encephalopathy; multiorgan dysfunction; an arterial $\mathrm{pH}$ $<7.33$; a $\mathrm{Pa}, \mathrm{O}_{2}<9.3 \mathrm{kPa}(70 \mathrm{mmHg})$ despite oxygen therapy; or haemodynamic instability.

\section{Experimental apparatus}

NPPV was delivered to the patient through a well-fitting manufactured nasal mask (Sullivan, Resmed Ltd, North Ryde, Australia, or Respironics Inc., Murrysville, PA, USA) or a custom-made mask applied with a chin strap. The ventilator used was a PS ventilator (Integra ${ }^{\mathrm{TM}}$; Saime, Savigny le Temple, France), with the recommended inspiratory unrebreathing circuit and an expiratory valve. The inspiratory pressure delivery slope (rate of pressurisation) could be set at four levels: 0 representing the steepest slope and 3 the most progressive slope. The inspiratory trigger was a flow trigger with six incremental sensitivities levels: 1 representing the most sensitive setting and 6 the least sensitive setting. Expiratory trigger was based on flow and set as a percentage of peak inspiratory flow. Oxygen therapy was delivered in six patients targeting $\mathrm{Sa}, \mathrm{O}_{2}$ at $92 \%$ during spontaneous breathing (SB). The inspired oxygen flow was maintained constant throughout the study (between 1 and $2 \mathrm{~L} \cdot \mathrm{min}^{-1}$ ). Oxygen flow was delivered on an inlet distal to the pneumotachograph during $\mathrm{SB}$ and on the inspiratory circuit at the exit of the ventilator during the ventilatory support.

\section{Measurements, data analysis and assessment of respiratory effort}

All data were recorded during a 5-min period following a 15-min period of stabilisation. Respiratory flow was measured using a pneumotachograph (Fleisch \#2; Fleisch, Lausanne, Switzerland), inserted between the nasal mask and the ventilator circuit distal to the expiratory valve, connected to a pressure transducer (MP 45 model, Validyne $\pm 2 \mathrm{cmH}_{2} \mathrm{O}$; Validyne, Northridge, CA, USA) and integrated to yield tidal volume $(V \mathrm{~T})$. Airway pressure $(P \mathrm{aw})$ was measured with a differential pressure transducer (MP 45 model, Validyne \pm $100 \mathrm{cmH}_{2} \mathrm{O}$; Validyne) on the nasal mask. $\mathrm{Sa}, \mathrm{O}_{2}$, respiratory rate and heart rate were also recorded during all stages of the study (Ultracap; Nellcorr Puritan-Bennett, Courtaboeuf, France). During the study periods, care was taken to avoid any leaks, with all the patients maintaining their mouths in a closed position and the mask being firmly applied on the face. During SB, the patient breathed through the nasal mask with the ventilator circuit disconnected.

Oesophageal (Poes) and gastric pressure $(P$ ga $)$ were measured using a $2.1-\mathrm{mm}$ external diameter catheter-mounted pressure transducer system with two integral transducers, mounted 5 and $35 \mathrm{~cm}$ from the distal tip (Gaeltec, Dunvegan, Isle of Skye, UK), inserted pernasally after careful administration of local anaesthesia (lidocaine 2\%; Astra Zeneca, Rueil-Malmaison, France) [3, 15]. This catheter was advanced gently until the distal tip was in the stomach and the proximal pressure transducer in the middle portion of the oesophagus. Appropriate placement of the oesophageal pressure transducer was assessed with the usual method [16]. Adequate placement of the gastric pressure transducer was ascertained by gentle manual pressure on the patient's abdomen to observe fluctuations in $\mathrm{Pga}$, as well as asking the patient to swallow and verifying that the sharp increase in Poes caused by oesophageal contraction was not observed on the $P$ ga tracing. Transdiaphragmatic pressure $(P \mathrm{di})$ was obtained by subtracting the $P$ oes signal from the $P$ ga signal. All the signals were digitised at $128 \mathrm{~Hz}$ and sampled for analysis using an analogic/numeric acquisition system (MP 100; Biopac Systems, Goletta, CA, USA), run on a PC computer (Elonex, Gennevilliers, France) with Acknowledge software.

Breathing pattern and $V^{\prime} \mathrm{E}$ were determined from the flow tracing. Inspiratory work of breathing (WOB), oesophageal (PTPoes) and diaphragmatic pressure time product (PTPdi) were computed from the Poes and $V \mathrm{~T}$ loops as previously described [17-23]. After elimination of the cycles modified by artefact, such as coughing or oesophageal spasms, 10-30 successive breaths were used to calculate the values.

\section{Protocol}

PS-NI was determined during the day, prior to the PS-I protocol, and was adjusted to achieve the optimal breathing pattern based on the increase in $V^{\prime} \mathrm{E}$ (with a target $V \mathrm{~T}$ of $15 \mathrm{~mL} \cdot \mathrm{kg}^{-1}$ ) and $\mathrm{Sa}, \mathrm{O}_{2}$ (with an increase of $\geqslant 1 \%$ ), decrease in respiratory rate and greatest achievable value for patient comfort. Inspiratory pressure was initially set at $1.1 \mathrm{kPa}$ $\left(8 \mathrm{cmH}_{2} \mathrm{O}\right)$ and was increased in steps of $0.1 \mathrm{kPa}\left(1 \mathrm{cmH}_{2} \mathrm{O}\right)$ to the level associated with the maximal comfort. The inspiratory pressure delivery slope (rate of pressurisation) was initially set at the lowest level (3) and was then progressively increased to meet the maximal comfort of the patient. The inspiratory trigger was set initially at the most sensitive value. Less sensitive inspiratory triggers were then proposed to meet the patient's best comfort. PS-NI was started with an expiratory trigger at $35 \%$ of maximal inspiratory flow and was then adjusted, in a random order, in steps of $5 \%$, from 25 to $50 \%$ of maximal inspiratory flow, to achieve the maximal patient comfort level. Positive endexpiratory pressure (PEEP) was not added as it has previously been shown that young stable patients with $\mathrm{CF}$ have minimal intrinsic PEEP [1]. The back-up rate was set at 10 breath$\mathrm{s} \cdot \mathrm{min}^{-1}$ in accordance with published guidelines [11, 12].

On the following day, the pressure measurements were made. The first period was a $15-$ min SB period. The patients 
breathed through a mouthpiece for the first $10 \mathrm{~min}$ and through the nasal mask during the last $5 \mathrm{~min}$. Recordings were made during these two SB periods, but only the nasal mask period was used for the comparison between the NPPV periods. This SB period was followed by a period of NPPV using the noninvasive settings determined from the previous day (PS-NI). After a second 15-min SB period, a series of different NPPV settings were performed to determine PS-I. PS-I was adjusted to provide optimal unloading of the respiratory muscles, reflected by the normalisation in $P$ oes and $P$ di swings, and also to provide the optimal synchrony between the patient and ventilator. The following parameters were titrated consecutively to achieve the invasive setting: level of inspiratory pressure; inspiratory pressure delivery slope (rate of pressurisation); and inspiratory and expiratory triggers sensitivity. Inspiratory pressure and the inspiratory pressure delivery slope were set at a level associated with the normalisation in $P$ oes and $P$ di swings (i.e. $5-8 \mathrm{cmH}_{2} \mathrm{O}$ ). The inspiratory trigger was set at the maximal sensitivity without auto-triggering or ineffective triggering. Auto-triggering was defined as the delivery of a positive-pressure waveform by the ventilator but not preceded by a negative deflection in $P$ oes. Ineffective triggering effort was defined by $>0.1 \mathrm{kPa}\left(1 \mathrm{cmH}_{2} \mathrm{O}\right)$ decrease in $P$ oes without a subsequent positive inspiratory pressure $[6,24]$. The quality of the inspiratory trigger was analysed as previously described $[25,26]$. In brief, the following parameters were computed from each pressure and/or flow trace: trigger pressure (maximum negative pressure deflection from baseline $(\Delta P)$ ), trigger time delay (time delay between the onset of inspiratory effort and the moment during which the airway pressure exceeds the expiratory pressure $(\Delta T)$ ) and the pressure time product (PTP), defined as the total area of the pressure-time curve below baseline during a cycle. The sensitivity of the expiratory trigger was set to obtain the shortest time delay between the $P$ di peak and the end of the positive inspiratory pressure. When PS-NI and PS-I were determined, and after a third 15-min SB period, two 15-min PS-NI and PS-I sessions were performed in a random order. The patients' comfort rating was evaluated at the end of each of these final PSNI and PS-I sessions using a visual analogue score, a valid test in young patients with $\mathrm{CF}$ [3]. The patients rated the intensity of comfort on an interval scale, which was a $10-\mathrm{cm}$ horizontal line with the words "least comfortable" and "most comfortable" on the left and the right end, respectively. The patients were instructed to place a vertical mark on the line such that its position relative to the two extremes indicated the magnitude of their comfort at the moment of the assessment. The comfort rating score was expressed in $\mathrm{mm}(0-100)$ and was the distance of the mark from the left hand of the visual analogue scale.

\section{Statistical analysis}

Data are given as mean $\pm \mathrm{SD}$. Repeated measures analysis of variance (ANOVA) were used to test the effect of the different conditions (SB, PS-NI and PS-I sessions) on the different variables measured. The SB period data used for the analysis were the mean of the data obtained during the different periods of SB. When ANOVA appeared appropriate, pair-wise comparisons were performed using the Bonferroni test. A p-value $<0.05$ was considered as the limit of significance.

\section{Results}

\section{Patients and ventilator settings}

All the patients tolerated the gastro-oesophageal catheter and the NPPV sessions well. In general, $1-2 \mathrm{~h}$ were necessary to fully assess and determine the noninvasive settings for each patient, and the mean duration to find the optimal PS-I was $30 \mathrm{~min}$. The clinical characteristics of the patients are presented in table 1. Although only small differences in all aspects of the ventilator settings were observed between PSNI and PS-I (table 2), the most common difference was the level of PS (higher in three patients and lower in two patients during PS-I compared to PS-NI). Despite the rate of inspiratory pressurisation (inspiratory pressure slope) being greater in one patient (patient 4) during PS-I compared to PSNI, the inspiratory trigger was set at a more (patient 7) and a less sensitive (patient 8) value. Furthermore, the expiratory trigger was set at a higher (patient 2, 4, 6) and a lower (patient 9) inspiratory flow threshold during PS-I. This modification of

Table 1.-Characteristics of the patients

\begin{tabular}{lc}
\hline Patients n & 10 \\
Male/female & $6 / 4$ \\
Age yrs & $15.4 \pm 3.0(10-21)$ \\
Height cm & $154 \pm 13(135-179)$ \\
Weight kg & $40.4 \pm 9.9(27-57)$ \\
VC \% pred & $46 \pm 11(33-58)$ \\
$\mathrm{FEV} 1 \%$ pred & $29 \pm 6(18-37)$ \\
$P a, \mathrm{O}_{2} \mathrm{mmHg}$ & $57.9 \pm 7.8(52-72)$ \\
$P \mathrm{a}, \mathrm{CO}_{2} \mathrm{mmHg}$ & $43.3 \pm 6.3(35-57)$ \\
$\mathrm{pH}$ & $7.40 \pm 0.02(7.36-7.45)$
\end{tabular}

Data are presented as mean \pm SD (range). VC: vital capacity; FEV1: forced expiratory volume in one second; $\mathrm{Pa}, \mathrm{O}_{2}$ : partial arterial oxygen pressure; $P \mathrm{a}, \mathrm{CO}_{2}$ : partial arterial carbon dioxide pressure. $1 \mathrm{mmHg}=0.133 \mathrm{kPa}$.

Table 2. - Comparison of the noninvasive (PS-NI) and invasive (PS-I) settings of noninvasive pressure support (PS) ventilation

\begin{tabular}{|c|c|c|c|c|c|c|c|c|}
\hline \multirow[t]{2}{*}{ Patients } & \multicolumn{2}{|c|}{ Level of $\mathrm{PS} \mathrm{cmH}_{2} \mathrm{O}$} & \multicolumn{2}{|c|}{ Inspiratory pressure delivery slope } & \multicolumn{2}{|c|}{ Inspiratory trigger $^{+}$} & \multicolumn{2}{|c|}{ Expiratory trigger $\% \S$} \\
\hline & PS-NI & PS-I & PS-NI & PS-I & PS-NI & PS-I & PS-NI & PS-I \\
\hline 1 & 14 & 16 & 2 & 2 & 1 & 1 & 35 & 35 \\
\hline 2 & 18 & 18 & 2 & 2 & 1 & 1 & 30 & 40 \\
\hline 3 & 17 & 18 & 2 & 2 & 1 & 1 & 35 & 35 \\
\hline $4^{\#}$ & 16 & 16 & 2 & 1 & 1 & 1 & 25 & 40 \\
\hline $5^{\#}$ & 16 & 16 & 2 & 2 & 1 & 1 & 35 & 35 \\
\hline 6 & 18 & 18 & 1 & 1 & 1 & 1 & 40 & 50 \\
\hline 7 & 12 & 12 & 1 & 1 & 4 & 2 & 30 & 30 \\
\hline $8^{\#}$ & 17 & 15 & 1 & 1 & 1 & 2 & 35 & 35 \\
\hline $9^{\#}$ & 11 & 10 & 1 & 1 & 1 & 1 & 35 & 25 \\
\hline $10^{\#}$ & 16 & 20 & 1 & 1 & 1 & 1 & 35 & 35 \\
\hline
\end{tabular}

${ }^{\#}$ : patients naive to noninvasive ventilation; ${ }^{\bullet}$ : four different levels of inspiratory pressure delivery slope were available with 0 representing the highest value and 3 the lowest peak inspiratory flow; ${ }^{+}$: six values of inspiratory trigger sensitivity were available with 1 representing the most sensitive setting and 6 the least sensitive setting; \&: expiratory trigger was set as a percentage of peak inspiratory flow. 
Table 3. - Breathing pattern and gas exchange changes in patients during spontaneous breathing compared with the ventilator set noninvasively (PS-NI) and the ventilator set invasively (PS-I)

\begin{tabular}{|c|c|c|c|}
\hline & Spontaneous breathing & PS-NI setting & PS-I setting \\
\hline$V \mathrm{~T} \mathrm{~L}^{\Uparrow}$ & $0.44 \pm 0.15$ & $0.69 \pm 0.29$ & $0.73 \pm 0.29$ \\
\hline RR breaths $\cdot \min ^{-1 \#}$ & $21.6 \pm 6.5$ & $22.1 \pm 6.1$ & $20.9 \pm 6.4$ \\
\hline$V^{\prime} \mathrm{E} \mathrm{L} \cdot \min ^{-1}$ & $8.9 \pm 1.8$ & $14.1 \pm 5.1$ & $14.2 \pm 4.6$ \\
\hline$V \mathrm{I}, \max \mathrm{L} \cdot \mathrm{s}^{-1}$ & $0.49 \pm 0.11$ & $0.83 \pm 0.21$ & $0.84 \pm 0.22$ \\
\hline$V \mathrm{~T} / T \mathrm{I} \mathrm{L} \cdot \mathrm{s}^{-1}$ & $0.35 \pm 0.09$ & $0.56 \pm 0.18$ & $0.55 \pm 0.17$ \\
\hline$T \mathrm{I} / T$ tot $\%{ }^{\#}$ & $43.6 \pm 4.5$ & $42.6 \pm 4.9$ & $43.4 \pm 4.0$ \\
\hline $\mathrm{Sa}, \mathrm{O}_{2} \%{ }^{\#}$ & $95.2 \pm 1.6$ & $95.4 \pm 1.7$ & $96.0 \pm 1.1$ \\
\hline Patient's comfort score ${ }^{+}$ & NA & $85 \pm 11 / 100$ & $95 \pm 6 / 100$ \\
\hline
\end{tabular}

Data are presented as mean $\pm \mathrm{SD} ; V \mathrm{~T}$ : tidal volume; RR: respiratory rate; $V^{\prime} \mathrm{E}$ : minute ventilation; $V \mathrm{I}$,max: maximal inspiratory flow; $V \mathrm{~T} / T \mathrm{I}$ : mean inspiratory flow; $T \mathrm{I} / T$ tot: inspiratory time-total respiratory time ratio; $\mathrm{Sa}, \mathrm{O}_{2}$ : arterial oxygen saturation as measured by pulse oximetry. ${ }^{\#}: \mathrm{p}<0.0001$ between the three conditions (ANOVA), differences between PS-NI and PS-I were not statistically significant; ${ }^{\uparrow}$ : nonsignificant (ANOVA); ${ }^{+}: \mathrm{p}=0.006$ between PS-NI and PS-I.

the expiratory trigger shortened the delay between the peak $P$ di and the end of the positive inspiratory pressure delivered by the ventilator by $60 \%$ (from $400 \pm 75$ to $211 \pm 163 \mathrm{~ms}$ during PS-NI and PS-I, respectively). Patient 5 had similar settings during PS-NI and PS-I. No differences were observed between the patients who were naive to NPPV $(n=5)$ and those on long-term NPPV $(\mathrm{n}=5)$. The patients on long-term NPPV used other ventilators at home, a comparison of the settings obtained during the study with those used at home was thus not possible.

\section{Breathing pattern and gas exchange}

As expected, the two ventilator settings induced a significant increase in $V \mathrm{~T}$ and $V^{\prime} \mathrm{E}$ (table 3 ). Peak inspiratory flow $(V I, \max )$ and mean inspiratory flow $(V \mathrm{~T} / T \mathrm{I})$ increased significantly during the two settings. Respiratory rate and the inspiratory time/duty cycle ratio ( $T I / T$ tot) decreased during the two ventilatory settings, but this did not reach statistical significance. This improvement in alveolar ventilation explained the significant increase in $\mathrm{Sa}_{\mathrm{a}} \mathrm{O}_{2} \quad(\mathrm{p}=0.02)$. Patient comfort score was significantly better during PS-I than during PS-NI (95 $\pm 6 / 100$ versus $85 \pm 11 / 100, p=0.006)$.

\section{Work of breathing and inspiratory and expiratory trigger}

The patients' inspiratory effort indexes are presented in table 4 and the individual results of PTPoes $\cdot \min ^{-1}$ and PTPdi $\cdot \mathrm{min}^{-1}$ are shown in figure 1 . All indices of respiratory effort decreased significantly with the two ventilatory settings, with no significant difference observed between PS-NI and PS-I.

In patients 8 and 9,13 and $20 \%$ of the breaths were auto-triggered during PS-NI. This auto-triggering was not observed during PS-I. Three other patients (patients 4, 5 and 6) had 4-20\% ineffective triggering efforts during PS-NI. During PS-I, this ineffective triggering disappeared in patients 4 and 6 , and was reduced to $<5 \%$ in patient 5 . The inspiratory trigger parameters calculated during the two settings are presented in table 5. No significant differences were observed between the two settings. No expiratory efforts, evaluated as an increase in Pga, were observed during the two settings.

\section{Discussion}

In stable young patients with CF, noninvasive PS ventilation effectively unloads the respiratory muscles and improves gas exchange irrespective of whether the ventilator is set up using a noninvasive clinical or a more invasive physiological approach. However, there is a moderate comfort benefit with the invasive method, which may be explained by the improved patient-ventilator synchronisation observed with this technique.

Experience with NPPV is limited in CF. Different ventilatory modes have been used, with volume-targeted ventilators being used in the first reports and PS ventilators in the more recent studies [3-5, 27-32]. With the exception of two recent studies $[3,31]$, in the majority of the studies the ventilatory settings were determined using noninvasive parameters. Granton and Kesten [31] measured Poes in two patients and FAUROUX et al. [3] showed that both PS and assist control- or volume-targeted ventilation were able to

Table 4. - Changes in the work of breathing between spontaneous breathing and the ventilator set noninvasively (PS-NI) and the ventilator set invasively (PS-I)

\begin{tabular}{|c|c|c|c|}
\hline & Spontaneous breathing & PS-NI setting & PS-I setting \\
\hline Swing $P_{\text {oes }} \mathrm{cmH}_{2} \mathrm{O}^{\#}$ & $19.8 \pm 4.6$ & $6.8 \pm 6.4$ & $5.2 \pm 4.2$ \\
\hline Swing $P$ di $\mathrm{cmH}_{2} \mathrm{O}^{\#}$ & $21.3 \pm 4.4$ & $7.5 \pm 6.2$ & $6.0 \pm 4.1$ \\
\hline PTPoes $\cdot$ breath $^{-1} \mathrm{cmH}_{2} \mathrm{O} \cdot \mathrm{s}^{-1 \#}$ & $20.0 \pm 6.3$ & $6.2 \pm 4.4$ & $5.5 \pm 3.4$ \\
\hline PTPdi $\cdot$ breath $^{-1} \mathrm{cmH}_{2} \mathrm{O} \cdot \mathrm{s}^{-1 \#}$ & $22.3 \pm 7.0$ & $5.2 \pm 4.3$ & $4.9 \pm 3.3$ \\
\hline PTPoes $\cdot \mathrm{min}^{-1} \mathrm{cmH}_{2} \mathrm{O} \cdot \mathrm{s}^{-1} \cdot \mathrm{min}^{-1 \#}$ & $405 \pm 91$ & $145 \pm 127$ & $121 \pm 88$ \\
\hline PTPdi $\cdot \mathrm{min}^{-1} \mathrm{~cm} \mathrm{H}_{2} \mathrm{O} \cdot \mathrm{s}^{-1} \cdot \mathrm{min}^{-1 \#}$ & $450 \pm 91$ & $129 \pm 125$ & $104 \pm 75$ \\
\hline WOB J cycle $^{-1}$ & $0.74 \pm 0.34$ & $0.41 \pm 0.42$ & $0.36 \pm 0.34$ \\
\hline WOB $\mathrm{J} \cdot \mathrm{min}^{-1}$ & $15.0 \pm 5.8$ & $9.5 \pm 10.4$ & $7.7 \pm 7.4$ \\
\hline WOB $\mathrm{J} \cdot \mathrm{L}^{-1 \#}$ & $1.64 \pm 0.38$ & $0.60 \pm 0.50$ & $0.49 \pm 0.36$ \\
\hline
\end{tabular}

Swing Poes: mean swing in oesophageal pressure; swing Pdi: mean swing in transdiaphragmatic pressure; PTPoes $\cdot$ breath $^{-1}$ : mean oesophageal

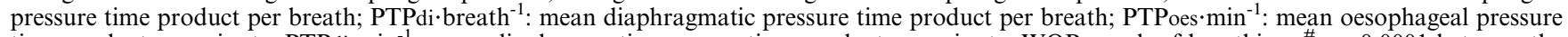
time product per minute; PTPdi $\cdot \mathrm{min}^{-1}$ : mean diaphragmatic pressure time product per minute; WOB: work of breathing. ${ }^{\#}$ : $\mathrm{p}<0.0001$ between the three conditions (ANOVA) with no significant difference between PS-NI and PS-I. 
effectively unload the respiratory muscles, as assessed by decreases in both PTPoes and PTPdi. Although the ability of PS and proportional assist ventilation to unload the
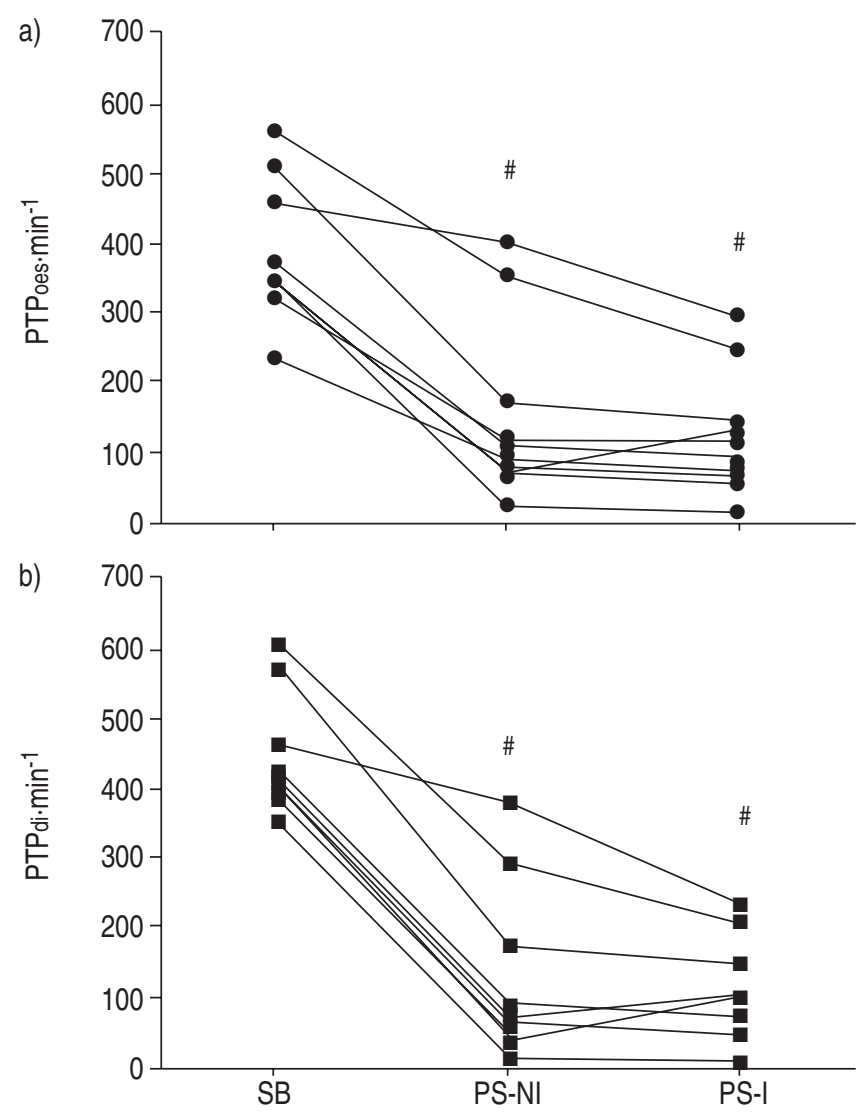

Fig. 1.- Individual variations of a) oesophageal pressure time product per minute (PTPoes $\cdot \mathrm{min}^{-1}$ ) and b) diaphragmatic pressure time product per minute (PTPdi $\cdot \mathrm{min}^{-1}$ ) between the ventilator set noninvasively (PSNI) and the ventilator set invasively (PS-I) compared with spontaneous breathing (SB). ${ }^{\#}: \mathrm{p}<0.0001$ compared to SB with no difference between PS-NI and PS-I.

Table 5.-Synchronisation of the patient with the ventilator and quality of the inspiratory trigger between the ventilator set noninvasively (PS-NI) and the ventilator set invasively (PS-I)

PS-NI setting PS-I setting

\begin{tabular}{lcc}
\hline Synchronisation & & \\
Auto-triggering & 13 and $30 \%(\mathrm{n}=2)$ & No auto-triggering \\
Ineffective & $4-20 \%(\mathrm{n}=3)$ & $5 \%(\mathrm{n}=1)$ \\
$\quad$ triggering efforts & & \\
Inspiratory trigger & $-0.49 \pm 0.27$ & $-0.54 \pm 0.18$ \\
$\Delta P \mathrm{cmH}{ }_{2} \mathrm{O}$ & $124 \pm 21$ & $161 \pm 72$ \\
$\Delta T \mathrm{~ms}$ & $0.047 \pm 0.018$ & $0.064 \pm 0.041$ \\
\hline $\mathrm{PTPaw} \mathrm{cmH}$ & $\mathrm{O} \cdot \mathrm{s}^{-1}$ & \\
\hline
\end{tabular}

Auto-triggering was defined by the delivery of a positive pressure by the ventilator not preceded by a negative deflection in oesophageal pressure ( $P$ oes) and ineffective triggering efforts by a $>0.1 \mathrm{kPa}\left(1 \mathrm{cmH}_{2} \mathrm{O}\right)$ decrease in $P$ oes that was not followed by a positive inspiratory pressure. The percentages represent the average breaths and the number of patients in whom these synchronisation problems occurred. The quality of the inspiratory trigger was evaluated on the following parameters: trigger pressure (maximum negative pressure deflection from baseline $(\Delta P)$ ), trigger time delay (time delay between the onset of inspiratory effort and the moment during which the airway pressure exceeds the expiratory pressure $(\Delta T)$ ) and the pressure time product (PTPaw) defined as the total area of the airway pressure below baseline during a cycle $[25,26]$. The differences between the inspiratory trigger during the two settings were not statistically significant diaphragm in adult patients with CF was recently demonstrated by the noninvasive recording of diaphragmatic surface electromyography [5], there are few clinical studies that have assessed respiratory mechanics and muscle activity during NPPV [6, 33-37]. These studies have quantified the unloading of the respiratory muscles by PS in stable chronic obstructive pulmonary disease patients [36] and during exhaustive exercise [35]; however, data on the ventilatory settings, in particular the values of the inspiratory and expiratory triggers, and the rate of inspiratory pressurisation (inspiratory pressure slope), are limited. In our experience, using this physiological approach to systematically evaluate all the domiciliary NPPV ventilators that are used in our clinical practice, the deleterious effect of trigger insensitivity on respiratory effort has been demonstrated (unpublished data).

Although a randomised design was incorporated into the current study throughout all the stages, it can be argued that the results could have been influenced by the order of adjustment, i.e. the study design used was randomised, but the ventilator settings established in the first part of the study was determined using the standard clinical method. However, our usual practice, consistent with that of most other centres, is to start with a clinical method which seems appropriate considering the goal of this type of mechanical ventilation is noninvasive.

This study highlights the benefits and limitations of a noninvasive and an invasive approach to the setting of NPPV in young patients with $\mathrm{CF}$. Both methods were equally effective in improving gas exchange and unloading the diaphragm, with the invasive approach offering a slight advantage in patient-ventilator synchronisation and comfort. Three important factors could explain the similar reductions in respiratory load during NPPV. First, the level of PS was not very different between the two settings. In five patients, the level of PS was the same and in the five others the difference ranged from $1-4 \mathrm{cmH}_{2} \mathrm{O}$ (table 2). Secondly, a ventilator was used which was able to reduce the patient's respiratory load almost as well as some of the more sophisticated and expensive intensive care unit ventilators. Indeed, the reduction in respiratory load reached almost $80 \%$, which was greater than the $50 \%$ reduction observed in a previous study in eight stable CF patients with a similar level of lung function [3]. As shown in figure 1, all the patients reduced their PTPoes and PTPdi during NPPV, with the quality of the inspiratory trigger during both PS-NI and PS-I being superior to that reported in previous studies [26]. Thirdly, it was observed that young patients with $\mathrm{CF}$ and severe lung disease were able to express, very precisely, their perception of breathing comfort. After a standardised training session, they were able to distinguish and perceive even small differences in the settings of inspiratory pressure, inspiratory and expiratory trigger, and the inspiratory pressure slope. This agreement between the respiratory comfort and the degree of unloading of the respiratory muscles has been observed previously and represents a useful tool to optimise ventilatory settings [3].

Nevertheless, the comfort quoted by the patient was significantly greater during PS-I than during PS-NI. Because breathing pattern, gas exchange and respiratory muscle unloading did not differ between the two settings, we hypothesise that this improved comfort is a consequence of the enhancement of patient-ventilator synchrony [8, 9]. Indeed, the auto-triggering and ineffective triggering efforts observed in the five patients during PS-NI were significantly less during PS-I. Although it is important to consider the clinical relevance of such findings, this study has the limitation of a short-term study, which does not allow any conclusion with regard to long-term benefits. Moreover, the difference in comfort between the invasive and noninvasive settings, although statistically significant, was moderate and possibly 
of small clinical relevance. However, one can hypothesise that improved comfort and patient-ventilator synchrony could translate into improved long-term ventilator compliance, which is crucial in patients with stable chronic respiratory insufficiency.

Diaphragmatic EMG (EMGdi) was not evaluated in this study. The main limitation of EMGdi is that the quantification of the reduction in respiratory effort is more difficult than with pressure indexes. Despite this, BECK et al. [38] have shown correlations between oesophageal EMGdi and $P$ di in adults with acute respiratory failure during different levels of ventilatory support [38]. The main advantage of EMGdi is the quantification of neural inspiratory time, which is less accurate with pressures indexes. PARTHASARATHY et al. [19] have shown that all indirect estimates of neural inspiratory time, such as the point of rapid decrease in $P$ oes and the $P$ di peak, have a poor agreement with the EMGdi measurements of neural TI. A further limitation of the current study is that it was a short-term study performed in awake patients during daytime. But it would be difficult to perform such detailed measurements of pressure during different conditions in children during sleep. Furthermore, daytime mechanical ventilation in awake patients has been reported to be equally effective in reversing chronic hypercapnia as nocturnal mechanical ventilation.

\section{Conclusions}

This study shows, in young patients with cystic fibrosis, that, with adequate skill and expertise, a noninvasive approach to setting up noninvasive positive pressure ventilation is as effective at unloading the respiratory muscles and improving gas exchange as a more invasive approach. However, adjustments made to the ventilator based on these invasive measurements can improve patient-ventilator synchrony and comfort. From these data, our recommendation would be that using a standard noninvasive clinical method to set up the ventilator is satisfactory in the majority of young patients with cystic fibrosis, but that more in-depth measurements should be reserved for those patients in which tolerance and compliance with noninvasive positive pressure ventilation is a problem.

\begin{abstract}
Acknowledgements. The authors would like to dedicate this work to late A. Harf. A. Harf is considered a major teaching father of respiratory physiology in France. He was a leader for all of us and awoke our interest in respiratory physiology and especially mechanical ventilation. Without his extending expertise, this work would not have been possible. We express our gratitude for having known a great physiologist, and a close friend, a model for all of us.
\end{abstract}

\section{References}

1. Hart N, Polkey MI, Clément A, et al. Changes in pulmonary mechanics with increasing disease severity in children and young adults with cystic fibrosis. Am J Respir Crit Care Med 2002; 166: 61-66.

2. Stromberg NO, Gustafsson PM. Ventilation inhomogeneity assessed by nitrogen washout and ventilation-perfusion mismatch by capnography in stable and induced airway obstruction. Pediatr Pulmonol 2000; 29: 94-102.

3. Fauroux B, Pigeot J, Polkey MI, Isabey D, Clément A, Lofaso F. In vivo physiological comparison of two ventilators used for domiciliary ventilation in children with cystic fibrosis. Crit Care Med 2001; 29: 2097-2105.

4. Milross MA, Piper AJ, Norman M, et al. Low-flow oxygen and bilevel pressure support. Effects on ventilation during sleep in cystic fibrosis. Am J Respir Crit Care Med 2001; 163: 129-134.

5. Serra A, Polese G, Braggion C, Rossi A. Non-invasive proportional assist and pressure support ventilation in patients with cystic fibrosis and chronic respiratory failure. Thorax 2002; 57: 50-54.

6. Vitacca M, Nava S, Confalonieri M, et al. The appropriate setting of noninvasive pressure support ventilation in stable COPD patients. Chest 2000; 118: 1286-1293.

7. Shapiro SH, Ernst P, Gray-Donald K, et al. Effects of negative pressure ventilation in severe chronic obstructive pulmonary disease. Lancet 1992; 340: 1425-1429.

8. Tobin MJ, Jubran A, Laghi F. Patient-ventilator interaction. Am J Respir Crit Care Med 2001; 163: 1059-1063.

9. Sassoon CH, Foster GT. Patient-ventilator asynchrony. Curr Opin Crit Care 2001; 7: 28-33.

10. Leung P, Jubran A, Tobin MJ. Comparison of assisted ventilator modes on triggering, patients' effort, and dyspnoea. Am J Respir Crit Care Med 1997; 155: 1940-1948.

11. Mechanical ventilation beyond the intensive care unit. Report of a consensus conference of the American College of Chest Physicians. Chest 1998; 113: 289S-321S.

12. Clinical indications for noninvasive positive pressure ventilation in chronic respiratory failure due to restrictive lung disease, COPD, and nocturnal hypoventilation - A Consensus Conference Report. Chest 1999; 116: 521-534.

13. Gaultier C, Boulé M, Allaire Y, Clément A, Burry A, Girard F. Determination of capillary oxygen tension in infants and children: assessment of methodology and normal values during growth. Bull Europ Physiopath Resp 1978; 14: 287294.

14. Quanjer PH. Standardized lung function testing. Eur Resp J 1993; 6: Suppl. 16, 5-30s.

15. Stell IM, Tompkins S, Lovell AT, Goldstone JC, Moxham J. An in vivo comparison of a catheter mounted pressure transducer system with conventional balloon catheters. Eur Resp J 1999; 13: 1158-1163.

16. Baydur A, Behrakis PK, Zin WA, Jaeger MJ, Milic-Emili J. A simple method for assessing the validity of the esophageal balloon technique. Am Rev Respir Dis 1982; 126: 788-791.

17. Brochard L, Pluskwa F, Lemaire F. Improved efficacy of spontaneous breathing with inspiratory pressure support. Am Rev Resp Dis 1987; 136: 411-415.

18. Brochard L, Rua F, Lorino H, Lemaire F, Harf A. Inspiratory pressure support compensates for the additional work of breathing caused by the endoctracheal tube. Anesthesiology 1991; 75: 739-745.

19. Parthasarathy S, Jubran A, Tobin M. Assessment of neural inspiratory time in ventilator-supported patients. Am J Respir Crit Care Med 2000; 162: 546-552.

20. Pepe PE, Marini JJ. Occult positive end-expiratory pressure in mechanically ventilated patients with airflow obstruction: the auto-PEEP effect. Am Rev Resp Dis 1982; 216: 166-169.

21. Fleury B, Murciano D, Talamo C, Aubier M, Pariente R, Milic-Emili $\mathbf{J}$. Work of breathing in patients with chronic obstructive disease in acute respiratory failure. Am Rev Resp Dis 1985; 131: 822-827.

22. Lessard MR, Lofaso F, Brochard L. Expiratory muscle activity increases intrinsic positive end-expiratory pressure independently of dynamic hyperinflation in mechanically ventilated patients. Am J Resp Crit Care Med 1995; 143: 459475.

23. Sassoon CSH, Light RW, Lodia R, Sieck GC, Mahutte CK. Pressure-time product during continuous positive airway pressure, pressure support ventilation and T-piece during weaning from mechanical ventilation. Am Rev Resp Dis 1991; 143: 459-475.

24. Nava S, Bruschi C, Rubini F. Respiratory response and 
inspiratory effort during pressure support ventilation in COPD patients. Intensive Care Med 1995; 21: 871-879.

25. Lofaso F, Brochard L, Hang T, Lorino H, Harf A, Isabey D. Home versus intensive care pressure support devices. Experimental and clinical comparison. Am J Respir Crit Care Med 1996; 153: 1591-1599.

26. Goulet R, Hess D, Kacmarek RM. Pressure vs flow triggering during pressure support ventilation. Chest 1997; 111: 1649-1653.

27. Hodson ME, Madden BP, Steven MH, Tsang VT, Yacoub MH. Noninvasive mechanical ventilation for cystic fibrosis, a potential bridge to transplantation. Eur Resp J 1991; 4: 524 527.

28. Piper AJ, Parker S, Torzillo PJ, Sullivan CE, Bye PT. Nocturnal nasal IPPV stabilizes patients with cystic fibrosis and hypercapnic failure. Chest 1992; 102: 846-850.

29. Regnis JA, Piper AJ, Henke KG, Parker S, Bye PTP, Sullivan CE. Benefits of nocturnal nasal CPAP in patients with cystic fibrosis. Chest 1994; 106: 1717-1724.

30. Padman R, Lawless S, Von Nessen S. Use of BiPAP by nasal mask in the treatment of respiratory insufficiency in paediatric patients: preliminary investigation. Pediatr Pulmonol 1994; 17: 119-123.

31. Granton JT, Kesten S. The acute effects of nasal positive pressure ventilation in patients with advanced cystic fibrosis. Chest 1998; 113: 1013-1018.
32. Gozal D. Nocturnal ventilatory support in patients with cystic fibrosis: comparison with supplemental oxygen. Eur Resp J 1997; 10: 1999-2003.

33. Nava S, Ambrosino N, Rubini F. Effect of nasal pressure support ventilation and external PEEP on diaphragmatic activity in patients with severe stable COPD. Chest 1993; 103: 143-150.

34. Porta R, Vitacca M, Clini E. Physiological effects of posture on mask ventilation in awake stable chronic hypercapnic COPD patients. Eur Respir J 1999; 14: 517-522.

35. Kyroussis D, Polkey MI, Hamnegard CH, Mills G, Green M, Moxham J. Respiratory muscle activity in patients with COPD walking to exhaustion with and without pressure support. Eur Respir J 2000; 15: 649-655.

36. Nava S, Fanfulla F, Frigerio P, Navalesi P. Physiological evaluation of 4 weeks of nocturnal nasal positive pressure ventilation in stable hypercapnic patients with chronic obstructive pulmonary disease. Respiration 2001; 68: 573583.

37. Aslanian P, El Atrous S, Isabey D, et al. Effects of flow triggering on breathing effort during partial ventilatory support. Am J Respir Crit Care Med 1998; 157: 135-143.

38. Beck J, Gottfried SB, Navalesi P, et al. Electrical activity of the diaphragm during pressure support ventilation in acute respiratory failure. Am J Respir Crit Care Med 2001; 164 : $419-424$ 